\title{
The in-flight blackbody calibration system for the GLORIA interferometer on board an airborne research platform
}

\author{
F. Olschewski ${ }^{1}$, A. Ebersoldt ${ }^{2}$, F. Friedl-Vallon ${ }^{2}$, B. Gutschwager ${ }^{3}$, J. Hollandt $^{3}$, A. Kleinert ${ }^{2}$, C. Monte ${ }^{3}$, C. Piesch ${ }^{2}$, \\ P. Preusse ${ }^{4}$, C. Rolf $^{1,4}$, P. Steffens ${ }^{1}$, and R. Koppmann ${ }^{1}$ \\ ${ }^{1}$ Physics Department, University of Wuppertal, 42097 Wuppertal, Germany \\ ${ }^{2}$ Karlsruhe Institute of Technology, 76344 Eggenstein-Leopoldshafen, Germany \\ ${ }^{3}$ Physikalisch-Technische Bundesanstalt, 10587 Berlin, Germany \\ ${ }^{4}$ Research Centre Juelich GmbH, 52428 Juelich, Germany
}

Correspondence to: F. Olschewski (olsch@uni-wuppertal.de)

Received: 21 March 2013 - Published in Atmos. Meas. Tech. Discuss.: 20 June 2013

Revised: 26 September 2013 - Accepted: 4 October 2013 - Published: 12 November 2013

\begin{abstract}
The Gimballed Limb Observer for Radiance Imaging of the Atmosphere (GLORIA) is a prototype of an imaging Fourier Transform Spectrometer (FTS) for PREMIER, a former candidate mission for ESA's Earth Explorer 7. GLORIA is deployed on board various research aircraft such as the Russian M55 Geophysica or the German HALO. The instrument provides detailed infrared images of the Upper Troposphere/Lower Stratosphere (UTLS) region, which plays a crucial role in the climate system. GLORIA uses a two-dimensional detector array for infrared limb observations in emission and therefore needs large-area blackbody radiation sources $(126 \mathrm{~mm} \times 126 \mathrm{~mm})$ for calibration.

In order to meet the highly demanding uncertainty requirements for the scientific objectives of the GLORIA missions and due to the sophisticated tomographic evaluation scheme, the spatial distribution of the radiance temperature of the blackbody calibration sources has to be determined with an uncertainty of about $0.1 \mathrm{~K}$. Since GLORIA is exposed to the hostile environment of the UTLS with mutable low temperature and pressure, an in-flight calibration system has to be carefully designed to cope with those adverse circumstances.

The GLORIA in-flight calibration system consists of two identical weight-optimised high-precision blackbody radiation sources, which are independently stabilised at two different temperatures. The two point calibration is in the range of the observed atmospheric infrared radiance emissions with $10 \mathrm{~K}$ below and $30 \mathrm{~K}$ above ambient temperature, respectively. Thermo-Electric Coolers are used to control the temperature of the blackbody radiation sources offering the
\end{abstract}

advantage of avoiding cryogens and mechanical coolers. The design and performance of the GLORIA in-flight calibration system is presented. The blackbody calibration sources have been comprehensively characterised for their spatially (full aperture) and spectrally (7 to $13 \mu \mathrm{m}$ ) resolved radiation properties in terms of radiance temperatures traceable to the International Temperature Scale (ITS-90) at the PhysikalischTechnische Bundesanstalt (PTB), the national metrology institute of Germany.

\section{Introduction}

The Gimballed Limb Observer for Radiance Imaging of the Atmosphere (GLORIA) is an airborne imaging Fourier Transform Spectrometer (FTS) deployed in the belly pod of the new German research aircraft HALO as well as on board the high-flying Russian research plane M55 Geophysica (Riese et al., 2014; Friedl-Vallon et al., 2014). It is the first instrument that utilises the infrared limb-imaging technique (Riese et al., 2005; Friedl-Vallon et al., 2006) for trace gas measurements in the Upper Troposphere/Lower Stratosphere (UTLS) region with unprecedented three-dimensional spatial resolution.

The UTLS plays a crucial role for the climate system (e.g. Solomon et al., 2007), as changes in the structure and in the chemical composition of this region result in particularly large changes in atmospheric radiative forcing leading to significant changes in surface temperature (e.g. Solomon et al., 
2010; Riese et al., 2012). Gettelman et al. (2011) state that this region exhibits complex dynamical, radiative, and chemical characteristics that place stringent spatial and temporal requirements on observing and modelling system. Dynamical processes such as stratosphere-troposphere exchange (STE) affect both the lowermost stratosphere (LMS) as well as the upper troposphere. Quantifying those processes that control the UTLS composition therefore represents an indispensable task (Riese et al., 2012). Important greenhouse gases such as water vapour and ozone, with steep spatial gradients in the UTLS, show large spatial and temporal variability as a result of STE (e.g. Stevenson et al., 2006; Ploeger et al., 2011). In particular, three-dimensional fields of water vapour, ozone, transport tracers, and chemically active species with high vertical (few 100s m) and horizontal resolution (few 10s km) as well as low uncertainties are mandatory to quantify physical and chemical processes controlling the composition and structure of the UTLS.

To achieve this objective, GLORIA uses a twodimensional detector array for detailed infrared limb observations in emission. The detector array consists of $256 \times 256$ individual detector pixels and can be commanded to read-out sub-frames. Up to $128 \times 128$ pixels are used by the Michelson FTS providing over 16000 simultaneous spectrally resolved limb views. This allows for measurements of atmospheric temperature fields, clouds parameters, aerosols, water vapour, ozone, and about ten other trace species. GLORIA is a prototype of an imaging FTS for a space instrument and serves as proof of concept for the InfraRed Limb Sounder of PREMIER, one former candidate of ESA's future Earth Explorer 7 mission (e.g. ESA, 2008, 2012; Preusse et al., 2009).

The calibration of infrared sounding instruments is always a major challenge especially for air- or space-borne experiments when in-flight calibration becomes necessary. As useful atmospheric measurements always depend highly on a well performed radiometric calibration, every effort should be made to create the most precise and reliable in-flight calibration sources. Due to the variable environmental conditions inside the instrument compartment of the aircraft it is not sufficient to calibrate the instrument on the ground only. Since GLORIA is exposed to the hostile environment of the UTLS at different flight altitudes with mutable low temperature and pressure $\left(T \sim-50^{\circ} \mathrm{C}, p<200 \mathrm{hPa}\right)$, the in-flight calibration system has to be carefully designed to cope with those adverse circumstances. Additional restrictions like weight limitations and power restraints are implied.

This paper describes the design and performance of the GLORIA in-flight calibration system, which has been comprehensively characterised for its spatially (full aperture) and spectrally (7 to $13 \mu \mathrm{m}$ ) resolved radiation properties in terms of radiance temperature traceable to the International Temperature Scale (ITS-90) at the Physikalisch-Technische Bundesanstalt (PTB), the national metrology institute of Germany. The blackbody radiation sources were tested under lab conditions as well as in a climatic and environmental test chamber in order to verify their performance in various atmospheric environments.

\section{The GLORIA instrument}

\subsection{Instrument description}

GLORIA is a joint project of Research Centre Juelich and Karlsruhe Institute of Technology, Germany. The GLORIA instrument concept is illustrated in Fig. 1. The heart of the GLORIA instrument is an imaging Michelson FTS operating in the infrared spectral region from 770 to $1400 \mathrm{~cm}^{-1}$ (Friedl-Vallon et al., 2006). It delivers spectrally resolved images of the Earth's limb with a vertical and horizontal fieldof-view (FOV) of $4.07^{\circ} \times 4.07^{\circ}$ covering tangent altitudes from about $4 \mathrm{~km}$ to flight level. Depending on the scientific goals of a flight, the horizontal detector range and thus the number of pixels used may be reduced, allowing for faster interferogram acquisition. The spectral resolution is adjusted to two different measuring modes: $1.25 \mathrm{~cm}^{-1}$ for the dynamics mode and $0.1 \mathrm{~cm}^{-1}$ for the chemistry mode, respectively. The chemistry mode at full spectral resolution is designed to gain a maximum number of trace gas species. For the dynamics mode, the spectral resolution is reduced allowing for a higher measurement frequency. Thus small-scale atmospheric features can be better resolved.

A two-lens aspheric optics with a beam diameter of approximately $36 \mathrm{~mm}$ is used to project the atmospheric radiation field onto the two-dimensional detector array. The detector module consists of the detector array (High Speed MCT $256 \times 256$ LW IDCA) mounted in a dewar with an integrated Stirling cooler. Readout electronics digitalizes the data and feeds them into a serial data stream. A typical setup for atmospheric measurements comprises of $128 \times 128$ pixels (vertical $\times$ horizontal), providing more than 16000 simultaneous interferograms in less than $20 \mathrm{~s}$.

The gimballed mount, which stabilises the line-of-sight (LOS) during flight, also allows for pointing the LOS at azimuth angles between 45 and $135^{\circ}$ with respect to the flight direction. This is essential for the tomographic retrieval approach in order to acquire three-dimensional images of atmospheric features (Ungermann et al., 2011). The gimbal's agility and the manoeuvrability of the instrument is also used to align the FTS with the in-flight blackbody calibration sources of GLORIA.

\subsection{Calibration requirements}

For the retrieval of temperature and trace gas distributions, measured detector signals have to be converted into atmospheric infrared radiance spectra. For the most accurate approach, absolute atmospheric radiance with low uncertainty has to be assigned to the measured spectra. For a sound temperature retrieval, the minimum requirement for the radiometric calibration of the instrument is a standard uncertainty 


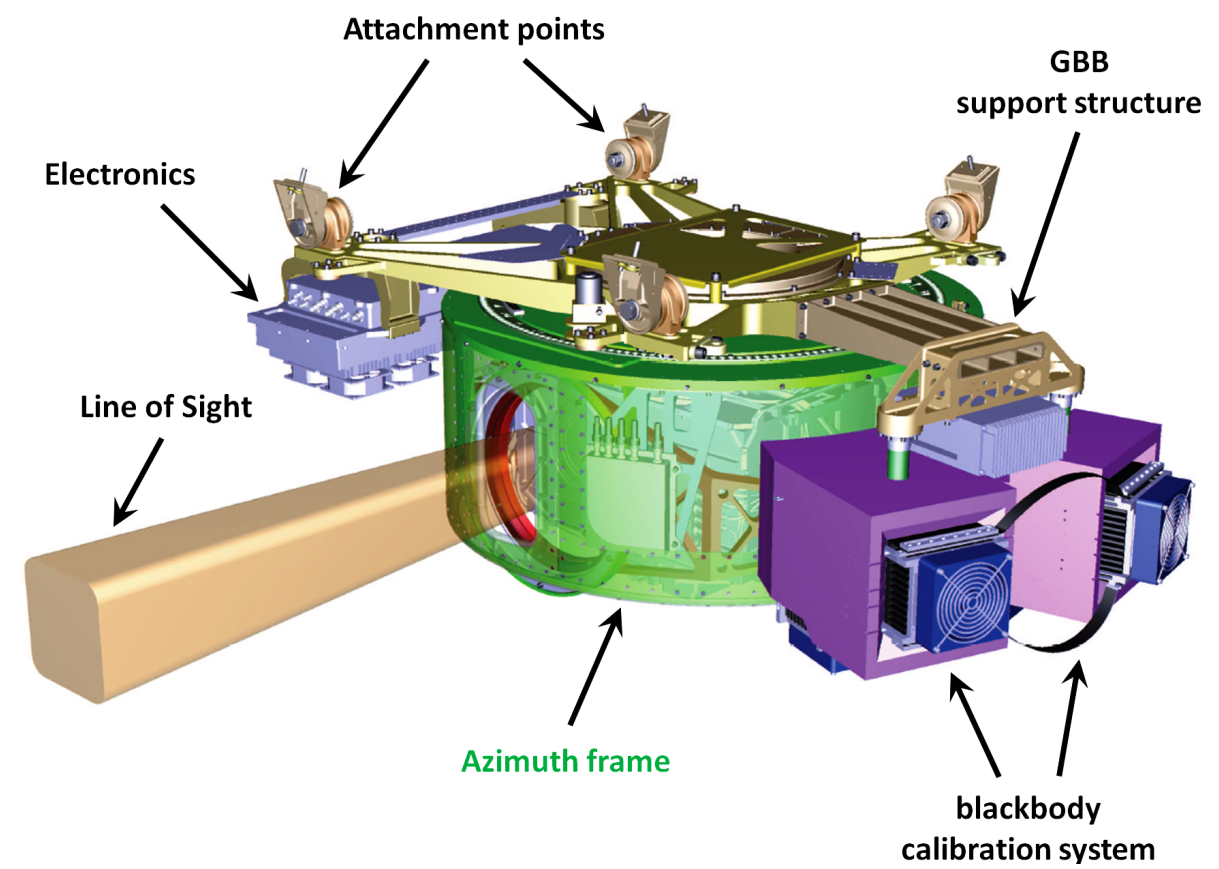

Fig. 1. Gimbal mounted GLORIA instrument with in-flight blackbody calibration system.

of less than $3 \%$. The target requirement for the GLORIA instrument is a standard uncertainty of less than $1 \%$ assuming that the statistical uncertainty (type A) (see ISO/IEC, 2008) of the measured spectra is significantly below $1 \%$ and therefore the total uncertainty of the spectral radiance results only from systematic (type B) (see ISO/IEC, 2008) and statistical uncertainties of the instrument calibration. This drives the requirements for the design of the in-flight blackbody calibration system and the calibration procedure in respect of spectral radiance uncertainties and radiance temperature measurements traceable to the International Temperature Scale (ITS-90). In this section, the requirements for the blackbody radiation sources in terms of temperature, temperature gradients, and emissivity are described and technical limitations are discussed.

Assuming the GLORIA measurement system has a linear response, only two calibration measurements using blackbody radiation sources at two different well-defined temperatures in the range of the atmospheric infrared radiance emissions are needed in order to radiometrically calibrate the GLORIA instrument including an offset correction. The transfer of the measured atmospheric spectra into atmospheric spectral radiance is given in Eq. (1):

$L_{\mathrm{a}}=S_{\mathrm{a}} \cdot \underbrace{\frac{B_{\mathrm{h}}-B_{\mathrm{c}}}{S_{\mathrm{h}}-S_{\mathrm{c}}}}_{\text {gain }}-\underbrace{\left(S_{\mathrm{c}} \cdot \frac{B_{\mathrm{h}}-B_{\mathrm{c}}}{S_{\mathrm{h}}-S_{\mathrm{c}}}-B_{\mathrm{c}}\right)}_{\text {offset }}$

with $L$ : spectral radiance, $S$ : measured spectrum, $B$ : spectral radiance of blackbody (Planck function), a: atmospheric, h: hot blackbody, c: cold blackbody.
The uncertainties in the radiances of the blackbodies directly contribute to the gain uncertainty $\left(u_{\text {gain }}\right)$ and thus to the uncertainty of the atmospheric spectral radiance. Therefore, the targeted uncertainty of $1 \%$ in the atmospheric radiance can only be met if the radiance of the calibration source is known to better than $1 \%$. This requires a high emissivity of the calibration sources and a precise determination of their temperature. The uncertainty introduced by the emissivity of the blackbodies $\left(u_{\epsilon}\right)$ is also influenced by the reflected radiation of the environment. In an isothermal environment, where the radiance of the environment is very similar to the emitted radiance of the blackbody, this error is negligible, but the larger the temperature difference between the blackbody and the sources of the reflected radiation becomes, the larger the uncertainty gets. Another critical parameter is the temperature difference between the two blackbody calibration sources. Ideally, the two blackbody calibration measurements should frame the radiance levels that occur in the atmosphere. Otherwise, extrapolation of the two point calibration is required, which generally entails larger uncertainties.

The offset is the radiance measured when there is no incoming radiation. It is generated by the instrument's selfemission. The most accurate way to determine the offset is to measure it directly by looking at a source with very low - ideally zero - radiance. For space-borne instruments, the "deep space" (DS) provides a very good cold blackbody radiance source as reference with virtually zero input. Measuring from an aircraft, however, the radiance coming from the atmosphere above limits the use of DS as a reference blackbody. The atmospheric radiance contribution has to be 


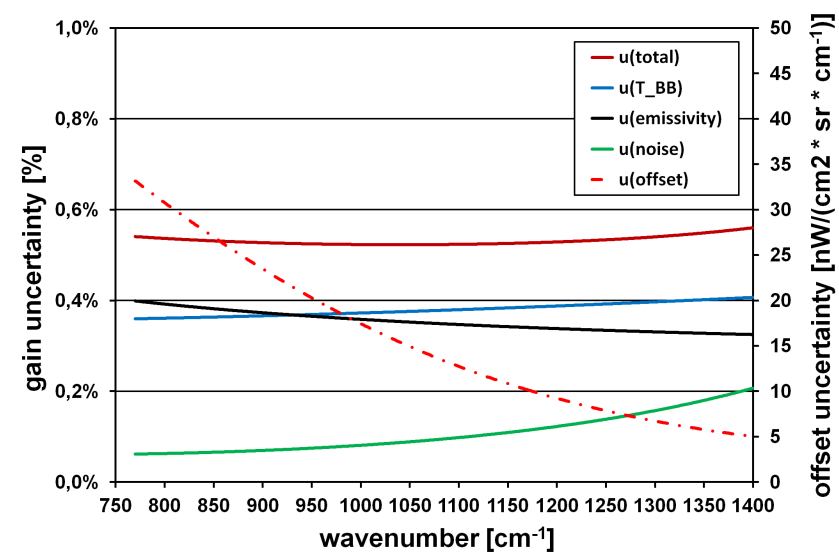

Fig. 2. Radiance uncertainty (gain and offset) according to requirements.

eliminated in order to use the upward measurement for calibration. For GLORIA, the conditions are even worse since the minimal zenith angle is $80^{\circ}$ due to the location inside the instrument compartment of the aircraft and therefore the optical path through the atmosphere is much longer leading to a much higher atmospheric signal. As reference measurements with virtually zero radiance input are not possible, the offset has to be determined by extrapolation of two blackbody calibration measurements: the larger the extrapolation, the larger the offset uncertainty $\left(u_{\text {off }}\right)$.

Optimising radiometric accuracy and feasibility, the following requirements have been established for the calibration system: the uncertainty in determination of the optical surface temperature shall be less than $100 \mathrm{mK}$ with a short term temperature stability better than $25 \mathrm{mK} \mathrm{min}^{-1}$. The emissivity needs to be better than 0.997 in the spectral range from 7 to $13 \mu \mathrm{m}$ while the temperature of the cold blackbody $(\mathrm{GBB}-\mathrm{C})$ is at least $10 \mathrm{~K}$ below ambient temperature. The temperature difference between the two calibration sources shall be at least $40 \mathrm{~K}$.

The temperature uncertainty $\left(u_{T}\right)$ of less than $100 \mathrm{mK}$ includes the uncertainty of the temperature measurement by platinum resistance thermometers (PRTs), thermal gradients between the temperature sensors and the optical surface, and thermal inhomogeneities within the effective area seen by the instrument. The relatively moderate requirement for the cold blackbody being operated only $10 \mathrm{~K}$ below ambient temperature is accounted for the risk of ice deposition on the optical surface of the blackbody calibration sources which could drastically change the emissivity and the radiance temperature. This in turn also determines the reasonable temperature difference between the two calibration sources, because the hot blackbody should not produce a much higher photon load than the atmospheric signal in order not to overload the detector. Since the offset determination by extrapolation of the two calibration measurements implies a troublesome uncertainty, an additional "quasi deep space" measurement should
Table 1. Technical specifications for the GLORIA in-flight blackbody calibration system.

\begin{tabular}{ll}
\hline Optical surface & $126 \mathrm{~mm} \times 126 \mathrm{~mm}$ \\
GBB-C temperature & $=$ ambient temperature $-10 \mathrm{~K}$ \\
GBB-H temperature & $=$ ambient temperature $+30 \mathrm{~K}$ \\
Temperature uncertainty & $<0.1 \mathrm{~K}$ \\
Emissivity & $>0.997$ \\
Spatial temperature inhomogeneity & $\leq 0.15 \mathrm{~K}$ \\
Temperature stability & $\leq 0.025 \mathrm{~K} \mathrm{~min}^{-1}$ \\
\hline
\end{tabular}

be established. Based on the requirements, $u_{\text {gain }}$ and $u_{\text {off }}$ for the wavenumber range of GLORIA have been calculated as shown in Fig. 2.

The following environmental parameters were used: it is assumed the ambient temperature inside the bellypod is $240 \mathrm{~K}$ which leads to a GBB-C temperature of $230 \mathrm{~K}$ and a GBB-H temperature of $270 \mathrm{~K}$. For the instrument a temperature of $220 \mathrm{~K}$ is supposed with an emissivity of 0.2 for the optical window. The total gain uncertainty $\left(u_{\text {total }}\right)$ for this configuration is below $0.6 \%$, which is well below the requirement of $1 \%$.

In addition to the above defined technical requirements for the in-flight blackbody calibration sources, a rigid and thorough calibration scheme has been established in cooperation with PTB to periodically characterise and calibrate the blackbodies traceable to the national standards of temperature before and after flight-operation.

\section{Design of the GLORIA in-flight blackbody calibration system}

As described in the previous section, the requirements for the in-flight blackbody calibration system pose a major challenge for its design. The GLORIA in-flight calibration system consists of two identical high-precision blackbody radiation sources (GBB-C and GBB-H), which are independently controlled at two different temperatures and emit radiation in the range of the atmospheric infrared radiance emissions (cf. Olschewski et al., 2012). In order to operate GBB-C at $10 \mathrm{~K}$ below and GBB-H at $30 \mathrm{~K}$ above ambient temperature respectively, Thermo-Electric Coolers (TECs) are used for temperature control offering the advantage of avoiding cryogens and mechanical coolers. An additional benefit of TECs is the dual utilisation for cooling and heating by just switching the direction of the electrical current.

The Atmospheric Physics group at the University of Wuppertal designed, built and tested the GLORIA in-flight blackbody calibration sources for its deployment on board different research aircraft. The design of the GLORIA in-flight blackbody calibration system fulfils all technical specifications as given in Table 1, it is weight-optimised and ensures minimal power consumption. 


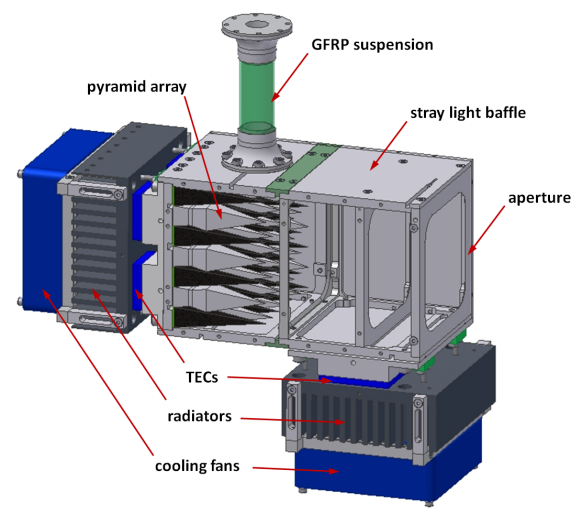

a)

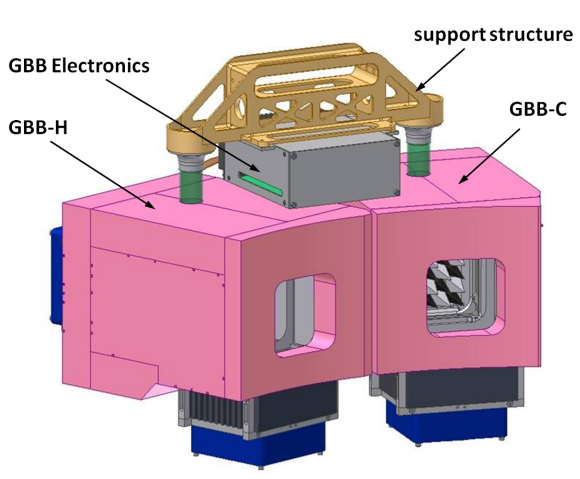

b)

Fig. 3. Design of a GLORIA BlackBody (a) and configuration of the complete GLORIA in-flight blackbody calibration system (b).

a)

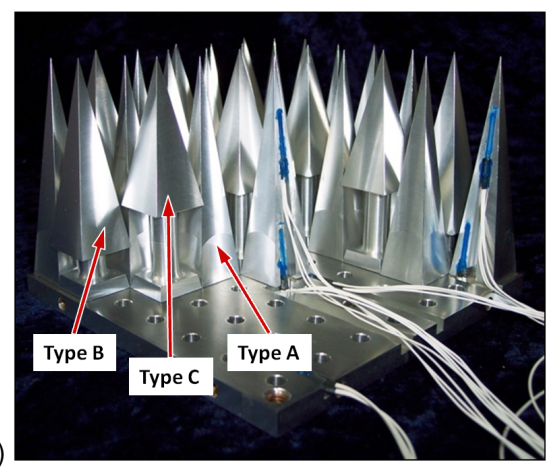

b)

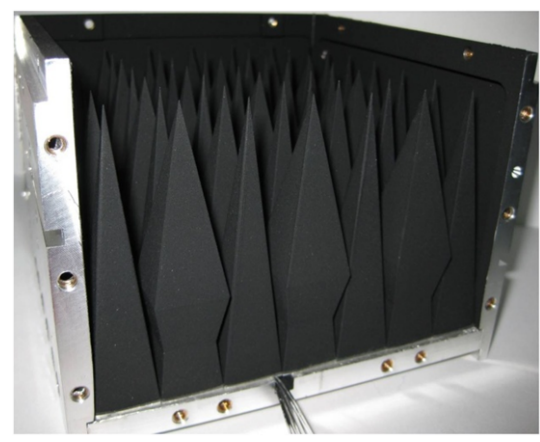

Fig. 4. Design of the optical surface: array of 49 individual pyramids (a) varnished with NEXTEL-Velvet Coating (b).

\subsection{Mechanical design and emissivity of a GLORIA BlackBody (GBB)}

Strict design requirements had to be applied in order to meet the scientific goals. Besides the highest precision of the optical surfaces with maximal emissivity ( $>0.997$ ), weight and space limitations had to be considered as well. Since GLORIA uses a large two-dimensional detector array for infrared limb observations, large-area blackbody radiation sources for radiometric calibration are necessary. Due to the FOV of the FTS the aperture of a GBB needs a minimum size of $102 \mathrm{~mm} \times 102 \mathrm{~mm}$ with an inhomogeneity in radiance temperature across the optical surface of less than $0.15 \mathrm{~K}$. Figure 3 illustrates the design of a GLORIA BlackBody (GBB).

In order to meet the specification of the required emissivity, the optical surface of a GBB with the dimension of $126 \mathrm{~mm} \times 126 \mathrm{~mm}$ consists of an array with 49 individual pyramids made of aluminium. Since surfaces perpendicular to the line-of-sight should be avoided as direct reflections diminish the emissivity of a blackbody, the pyramids have different square bases on different levels (see Fig. 4). The base of type $\mathrm{A}$ is $18 \mathrm{~mm} \times 18 \mathrm{~mm}$ whereas type $\mathrm{B}$ and type $\mathrm{C}$ have a slightly bigger base $(20 \mathrm{~mm} \times 20 \mathrm{~mm})$.
The NEXTEL-Velvet Coating 811-21 that is used as surface finish for the pyramids as well as for the inner walls of the casing has a measured emissivity of greater than 0.967 in the spectral range from 5 to $12 \mu \mathrm{m}$ (e.g. Lohrengel and Todtenhaupt, 1996). Due to the steep angles of the pyramid apexes $\left(83-79^{\circ}\right)$ most of the incoming radiation, which is not absorbed, is reflected into the back, and thus the effective emissivity is enhanced. Since the bases of type B and type C pyramids are elevated (see Fig. 4), light traps are formed which prevent direct back reflection. The NEXTEL surface coating has a nearly Lambertian radiation characteristic. Geometry factors for the pyramid array in a mediumsize box $(L=182 \mathrm{~mm})$ have been calculated for the radiative exchange between each area element of the pyramids and the aperture according to Howell (2010) (see Eq. 2). Weighted with the surface finish emissivity of 0.967 , the calculations yield an effective emissivity of 0.9996 . The measured $u_{\epsilon}$ of the coating is about $1 \%$ leading to an effective $u_{\epsilon}$ of 0.0003 .

$$
F_{1-2}=\frac{1}{\pi \cdot A^{2}}\left\{\begin{array}{l}
\ln \frac{\left[A^{2}\left(1+B^{2}\right)+2\right]^{2}}{\left(Y^{2}+2\right) \cdot\left(X^{2}+2\right)} \\
+\left(Y^{2}+4\right)^{1 / 2}\left[Y \tan ^{-1} \frac{Y}{\left(Y^{2}+4\right)^{1 / 2}}-X \tan ^{-1} \frac{X}{\left(Y^{2}+4\right)^{1 / 2}}\right] \\
+\left(X^{2}+4\right)^{1 / 2}\left[X \tan ^{-1} \frac{X}{\left(X^{2}+4\right)^{1 / 2}}-Y \tan ^{-1} \frac{X}{\left(X^{2}+4\right)^{1 / 2}}\right]
\end{array}\right\}
$$



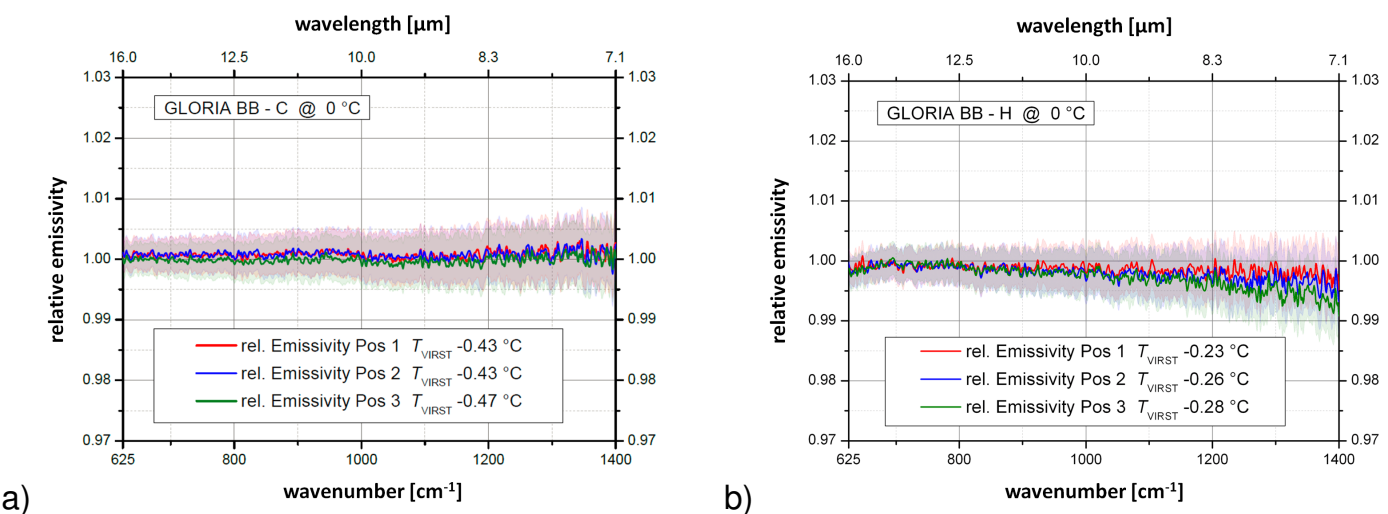

Fig. 5. Relative spectral emissivity of GBB-C (a) and GBB-H (b). The shaded areas represent the uncertainty of each measurement (two sigma).

with $a=126 \mathrm{~mm}$ (pyramid array width), $b=102 \mathrm{~mm}$ (aperture width), $c=182 \mathrm{~mm}$ (box length), $A=a / c, B=b / a$, $X=A \cdot(1+B), Y=A \cdot(1-B)$.

Measurements at PTB, the national metrology institute of Germany, confirm the results of the emissivity calculation. The measurements were performed at a temperature of $0^{\circ} \mathrm{C}$. Figure 5 shows the relative spectral emissivity in the spectral range from 7 to $16 \mu \mathrm{m}$ of both blackbody calibration sources measured at three positions on the pyramid array (pyramid type A, B, C marked as 1, 2, 3 in Fig. 6). The shaded areas in the panels represent the two sigma confidence interval. With respect to the uncertainties of these measurements neither significant deviations from 1 are visible nor are local effects apparent for both blackbody calibration sources, which corroborates the assumption about the emissivity and verifies the absence of spectral features.

The optical surface of a GBB is temperature-controlled by a system consisting of an assembly of four two-stage Thermo-Electric Coolers (TECs). Details of the thermal design are given in Sect. 3.2. In Fig. 6 the positions of the TECs on the back side of the optical surface are marked in green. The temperature of the optical surface is measured at specific pyramids using platinum resistance thermometers (PRTs). Locations and positions of the ten PRTs are illustrated in Figs. 4 and 6. The labelled red circles correspond to the individual temperature sensors.

The aluminium casing which surrounds the optical surface is partly thermally decoupled, while the front part serves as a stray light baffle which is also temperature-controlled by TECs (see Fig. 3a). The stray light baffle is operated at a slightly lower temperature in order to act as a water vapour trap to inhibit condensation on the black optical surface. The in-flight blackbody calibration sources are suspended by GFRP (Glass-Fibre-Reinforced-Plastic) tubes for thermal decoupling. In order to reduce the adverse influence of the thermal environment, the GBBs are covered with a $50 \mathrm{~mm}$ insulation made of extruded polystyrene foam (XPS) sheets. The outermost layer of the cover is composed

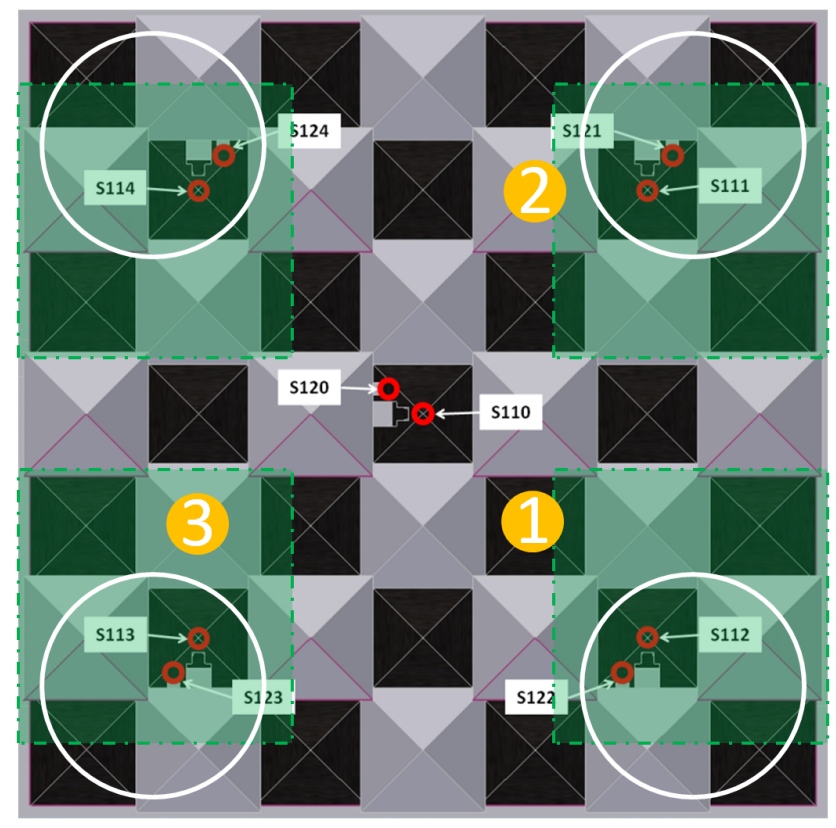

Fig. 6. Array configuration: the little red circles show the locations of the PRTs, the greenish areas indicate the positions of the TECs on the backside of the array, the white circles represent the FOV of the corner pixels of the detector array. The numbered orange spots mark the areas of the spectral measurements.

of aluminium foils for EMC (Electro-Magnetic Compatibility) reasons. The overall weight of one GBB is $9.5 \mathrm{~kg}$.

\subsection{Thermal design}

In order to achieve the desired blackbody temperatures for the calibration of the FTS detector array, TECs are used for temperature control. The heat input under various in-flight conditions has been estimated for the cold blackbody GBB$\mathrm{C}$ to be less than $1.5 \mathrm{~W}$ for the pyramid array and less than $3.5 \mathrm{~W}$ for the stray light baffle, respectively. This is achieved 
a)
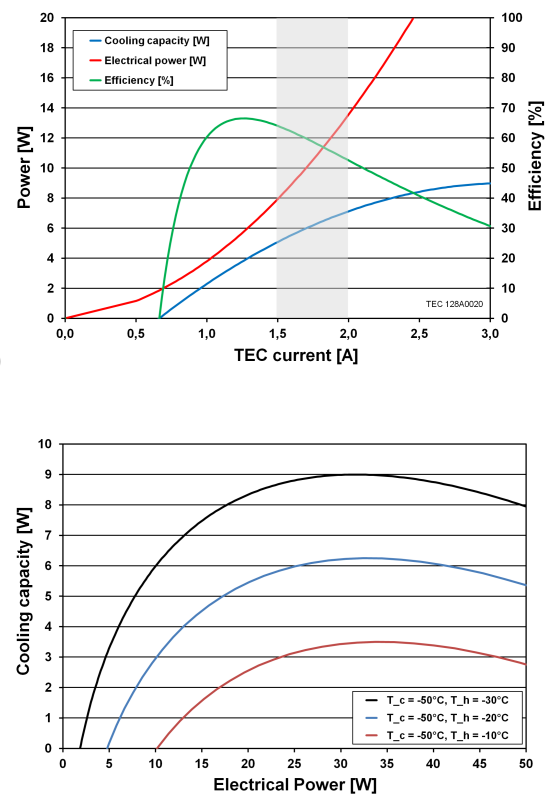

b)
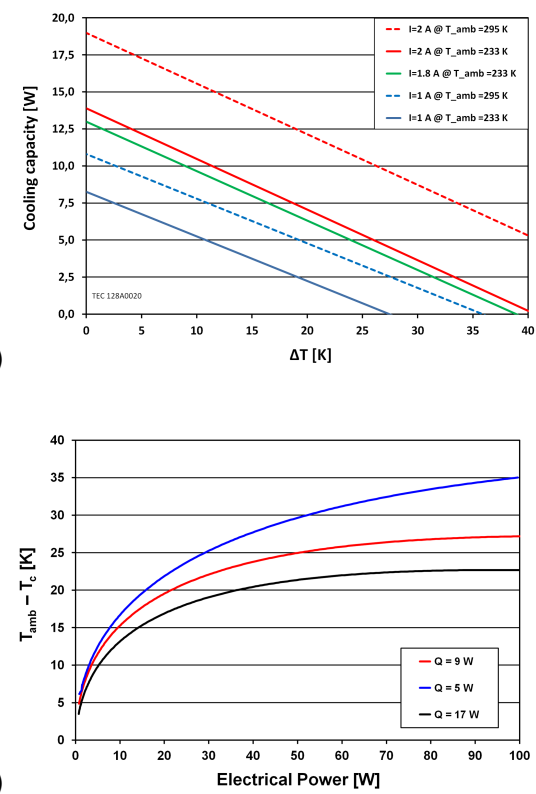

Fig. 7. TEC 128A0020 performance: (a) calculation for $T_{\mathrm{C}}=-50{ }^{\circ} \mathrm{C}$ and $T_{\mathrm{h}}=-30^{\circ} \mathrm{C}$ as a function of TEC current, (b) cooling capacity at various ambient temperatures, (c) cooling capacity at various temperature differences between $T_{\mathrm{h}}$ and $T_{\mathrm{c}}$ with $T_{\mathrm{c}}=-50^{\circ} \mathrm{C}$ and $(\mathbf{d})$ maximum achievable $\Delta T$ as a function of electrical power for different external heat loads $Q$.

by using XPS sheets for thermal protection. Those relatively small heat loads can easily be handled by standard TECs.

Unfortunately, cool-down of the GBBs cannot start before aircraft take-off due to the risk of water vapour contamination. For this reason, the GLORIA in-flight calibration system is more or less at ambient temperature before take-off of the aircraft. Since it is highly desirable to be operational in the UTLS region as early in the flight as possible, the time constants for reaching the operating temperatures of the blackbodies had to be optimised.

\subsubsection{Physical properties and performance of selected TECs}

Since TECs show highly nonlinear temperature dependence particularly with regard to their thermoelectric power, thermal conductivity, and internal resistance, it is important to carefully select the right type for the envisaged deployment. In addition, available voltages and power consumption must also be considered, since the power available for the blackbody calibration system is very limited. For temperature stabilisation of the GBB optical surface, the TEC type Peltron 128A0020 was selected and for the stray light baffle temperature control the TEC type Peltron 128A2427, respectively. Characteristics of the TECs for an ambient temperature $\left(T_{\mathrm{amb}}\right)$ of $-30^{\circ} \mathrm{C}$ are given in Table 2 including the one used for the GBB prototype (Peltron 128A2013).

Cooling capacity, power consumption and efficiency as a function of various parameters like TEC current and ambient temperature have been calculated for TEC 128A0020 and for TEC 128A2427, respectively. The results for TEC 128A0020 are shown in Fig. 7. For a cold side temperature $\left(T_{\mathrm{c}}\right)$ of $-50{ }^{\circ} \mathrm{C}$ and a hot side temperature $\left(T_{\mathrm{h}}\right)$ of $-30^{\circ} \mathrm{C}$, cooling capacity, power consumption and efficiency as a function of TEC current are given in Fig. 7a. The shaded area (TEC current between 1.5 and $2 \mathrm{~A}$ ) indicates the range for optimum performance. Figure $7 \mathrm{~b}$ illustrates TEC performance for various ambient temperatures. The cooling capacity is plotted as a function of $\Delta T$, the temperature difference between $T_{\mathrm{h}}$ and $T_{\mathrm{c}}$ of the TEC. In case of optimal heat dissipation on the hot side, $T_{\mathrm{h}}$ should be close to $T_{\mathrm{amb}}$. Thus, $\Delta T$ is almost equal to the difference between $T_{\mathrm{amb}}$ and $T_{\mathrm{c}}$. The cooling capacity as a function of electrical power for various temperature differences between $T_{\mathrm{c}}$ and $T_{\mathrm{h}}$ is shown in Fig. 7c. The high dependency of the TEC performance on $T_{\mathrm{h}}$ is obvious. Therefore, every effort was made to keep the temperature of the hot side as low as possible. The maximum $\Delta T$ as a function of electrical power has been calculated for different external heat loads $Q$ (see Fig. 7d). The results clearly show that the dependence of the maximum achievable $\Delta T$ on the electrical power is highly nonlinear. That means in practice that a power increase above a certain value is not reasonable because it will not significantly lower $T_{\mathrm{c}}$.

In order to save power and to improve the performance of the temperature control, an assembly of four two-stage Peltron $128 \mathrm{~A} 0020$ is used to generate a stable and homogeneous radiance temperature field across the optical surface of each GBB. For the temperature control of the stray light baffle two single-stage TEC type Peltron 128A2427 are applied. 
a)

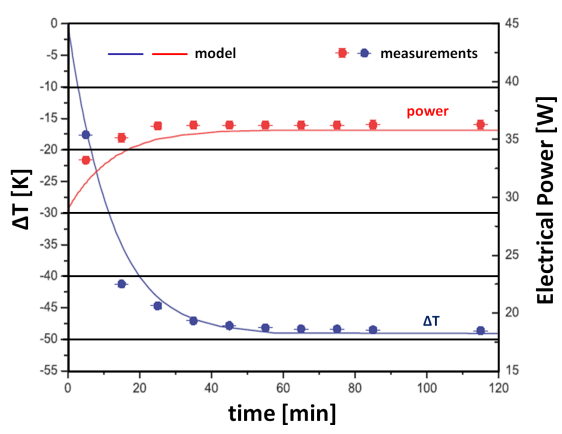

b)

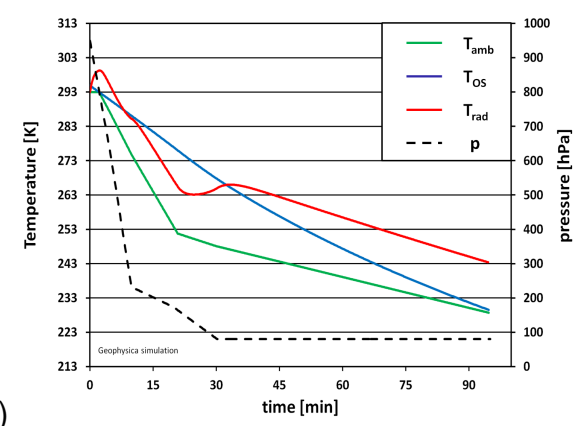

Fig. 8. Model simulation for the thermal behaviour during ascent: (a) the GBB prototype with a constant electrical current of $3 \mathrm{~A}$ and (b) optimal cooling of GBB-C optical surface during a Geophysica ascent (calculated for $I_{\mathrm{TEC}}=1.5 \mathrm{~A}$ ).

Table 2. Physical properties of selected TECs at $-30{ }^{\circ} \mathrm{C}$.

\begin{tabular}{lcccc}
\hline Type & Size & $\begin{array}{c}\text { Thermoelectric } \\
\text { power } \\
{\left[\mathrm{V} \mathrm{K}^{-1}\right]}\end{array}$ & $\begin{array}{c}\text { Thermal } \\
\text { conductivity } \\
{\left[\mathrm{W} \mathrm{K}^{-1}\right]}\end{array}$ & $\begin{array}{c}\text { Internal } \\
\text { resistance } \\
{[\Omega]}\end{array}$ \\
\hline 128A0020 & $40 \times 40$ & 0.042 & 0.28 & 2.8 \\
128A2427 & $62 \times 62$ & 0.042 & 0.89 & 0.94 \\
$128 \mathrm{~mm} 2013^{*}$ & $50 \times 50$ & 0.042 & 1.21 & 1.28 \\
\hline
\end{tabular}

* Used for the prototype.

\subsubsection{Heat load management}

Since the effectiveness of TECs and thus the achievable lowest temperature is primarily determined by the temperature of the hot side of the TECs, passive and active elements for heat dissipation were designed with great effort. Massive radiators combined with cooling fans work as heat sinks. The efficiency of the heat sink is highly dependent on the air pressure and the ambient temperature which in turn is determined by the flight level of the aircraft and the heat load inside the instrument compartment.

Considering the power limitation and the weight margin, a radiator with $0.6 \mathrm{~K} \mathrm{~W}^{-1}$ and a cooling fan with an airflow of $252 \mathrm{~m}^{3} \mathrm{~h}^{-1}$ were selected for each thermal control unit. The radiators are directly positioned on top of the TECs to avoid additional thermal resistance. They are mechanically fixed to the thermal control plate on the opposite side of the TECs using low heat conducting material. This sandwich structure also holds the TECs in place.

\subsubsection{Thermal performance during ascent}

It is a primary goal that the blackbody calibration system is ready for service as soon as possible after take-off. The most time consuming operation is to reduce the temperatures from about $+20^{\circ} \mathrm{C}$ on the ground to $-30^{\circ} \mathrm{C}$ inside the instrument compartment of the aircraft at flight level. Those times depend on the heat capacity of the aluminium structure as well as the cooling efficiency. The cooling efficiency on the other hand is contingent on the available electrical power and the performance characteristics of the TECs. The thermal behaviour of the GBB prototype during ascent simulation with a constant electrical current of $3 \mathrm{~A}$ is shown in Fig. 8a with $\Delta T$ referring to the initial temperature. Comprehensive model simulations yield a heat load of $25 \mathrm{~W}$ for the achieved temperature difference of $47 \mathrm{~K}$. Cooling down the GBB-C optical surface with $I_{\mathrm{TEC}}=1.5 \mathrm{~A}$ result in an optimal performance. The results of the simulation shown in Fig. $8 \mathrm{~b}$ are based on a simulated Geophysica flight reaching an altitude of $19 \mathrm{~km}$.

\subsection{Accuracy of calibration measurements}

Based on the final design of the GBBs, uncertainty calculations for various operating temperatures of GBB-C and GBB-H were performed. Environmental conditions were confined to the parameters used in Sect. 2.2. Figure 9 illustrates how $u_{\text {gain }}$ and $u_{\text {off }}$ depend on the operational temperatures of GBB-C and GBB-H. It is apparent that even with GBB-C at a temperature as high as $240 \mathrm{~K}$ and GBB-H just $30 \mathrm{~K}$ above, the total gain uncertainty is about $0.5 \%$. Operating GBB-C at a temperature of $230 \mathrm{~K}$ and GBB-H at $270 \mathrm{~K}$ will result in a total gain uncertainty of less than $0.4 \%$. This configuration leads to a maximum offset uncertainty of about $25 \mathrm{nW}\left(\mathrm{cm}^{-2} \mathrm{srcm}^{-1}\right)^{-1}$. Detailed calculations show that the temperature uncertainty $u_{T}$ is the dominant factor for the total accuracy. The uncertainty of the emissivity is about one order of magnitude smaller.

\subsection{Instrumentation and GBB electronics}

For each GBB, 24 PRTs $(100 \Omega)$ type DIN B/10 with a nominal $u_{T}$ of $0.03 \mathrm{~K}$ at $0{ }^{\circ} \mathrm{C}$ are used for temperature monitoring and control. Five pyramids of each optical surface are equipped with two temperature sensors each, one close to the apex and one close to the base. Their locations and positions are illustrated in Figs. 4a and 6. For controlling the temperature in the four sectors of the optical surface the mean value of apex and base temperature of the relevant pyramid is used. Fourteen more PRTs are used for monitoring the temperature of the casing as well as of the radiators. In order to achieve 
a)

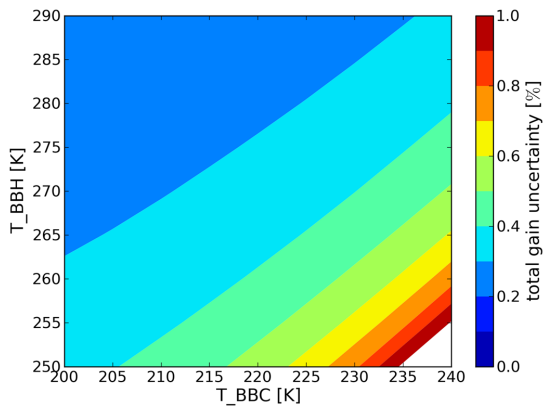

b)

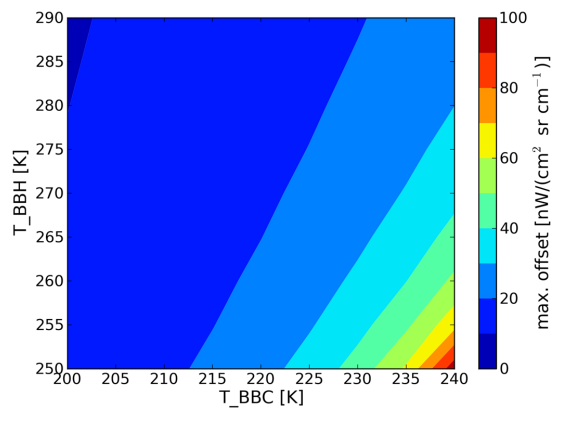

Fig. 9. Radiance uncertainty as a function of GBB-C and GBB-H temperatures: (a) total gain uncertainty and (b) maximum offset uncertainty.

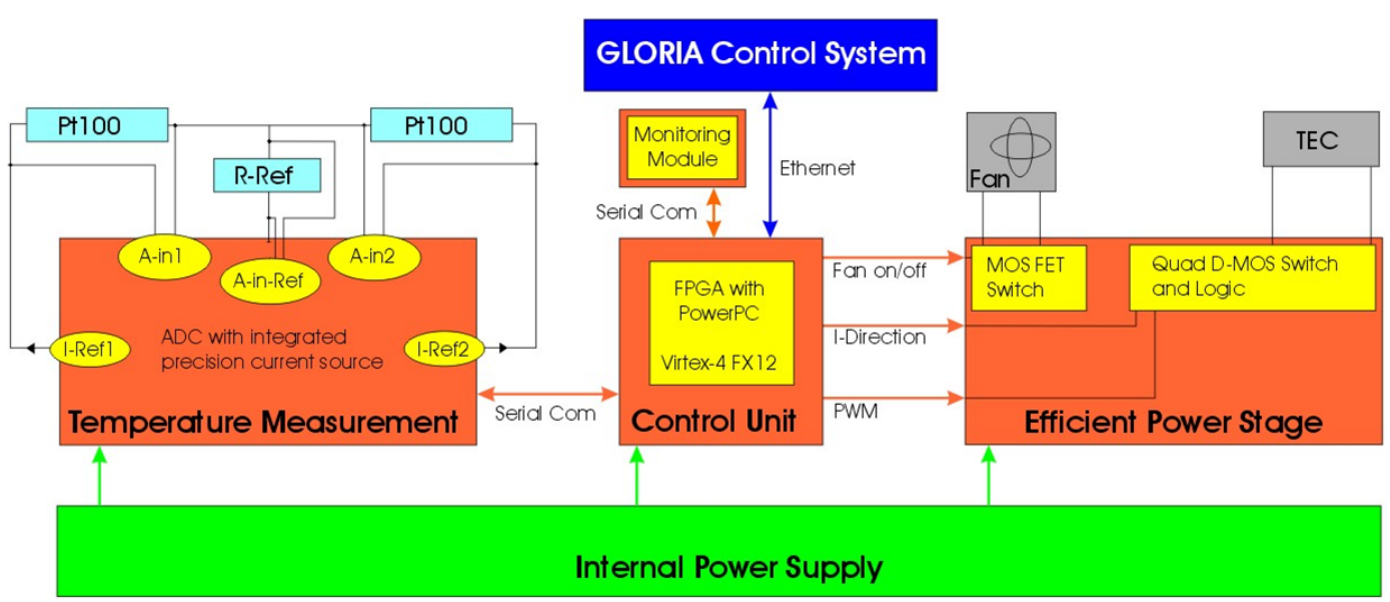

Fig. 10. Schematic of the GBB-electronics: power supply, temperature measurement module, control unit and the efficient power stage for controlling the TECs and the cooling fans.

a low uncertainty in the determination of the calibration parameters, it is more important to measure precisely the actual temperature and the temperature distribution on the black optical surface than to finely adjust a certain value.

The GBB electronics, developed and built at the Institute for Data Processing and Electronics (IPE) of KIT, also provides the power for all electrical components and is housed in a separate box located above the GBBs (see Fig. 3b).

The technical requirements for the GBB electronics include low weight, low power consumption and low heat generation implying low power dissipation. To fulfil the calibration requirements, extremely precise temperature measurements are supplied. The GBB electronics also controls the TECs and the cooling fans and delivers all GBB data to the GLORIA data acquisition system. The GBB electronics itself consists of four modules (see Fig. 10): the temperature measurement module for 48 PRTs, an efficient power stage for controlling 12 TECs and 4 cooling fans, a communication and control unit (Xilinx Virtex-4 FX12 Mini-Module) and a power supply for all internal electric voltages.

Since the TECs and the cooling fans are operated at $15 \mathrm{~V}$, the maximum available current for the TECs is only $2.3 \mathrm{~A}$, resulting in a maximum electrical power for cooling the optical surfaces of $138 \mathrm{~W}$. Heat dissipation from the TEC power stage and from the power supply was carefully designed using high heat conducting materials and an effective lowweight radiator attached to the GBB electronics box.

In addition the GBB electronics components are selected for airworthiness, to endure low temperature and low pressure, and for effective heat dissipation on ground and during flight. They are designed to withstand extreme environments from the tropics to the tropopause. Safety shut-down in case of overheat, circuit malfunction or electrical short is included. The GBB electronics successfully passed all vibrational, electro-magnetic compatibility and environmental tests proving to be suitable for deployment on an airborne platform.

\section{GLORIA BlackBody performance}

To assure optimal performance of the GLORIA in-flight blackbody calibration system, it is important to know its specific characteristics in order to predict its behaviour during flight. A thermal model was set up to study various environmental settings in a computer simulation. The various 
a)
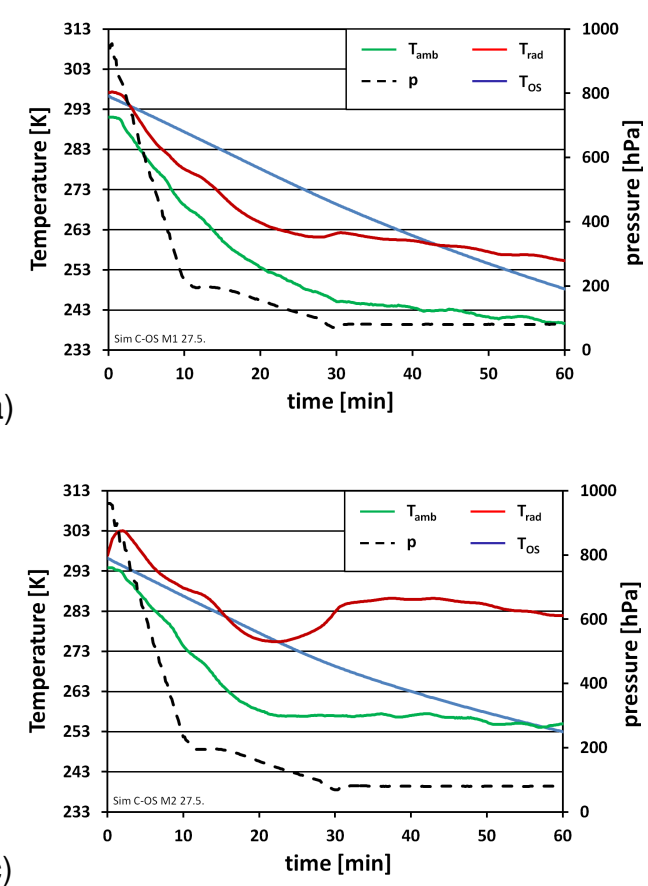

b)

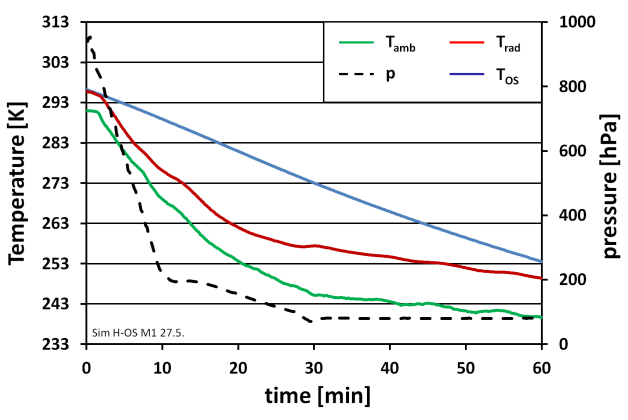

d)

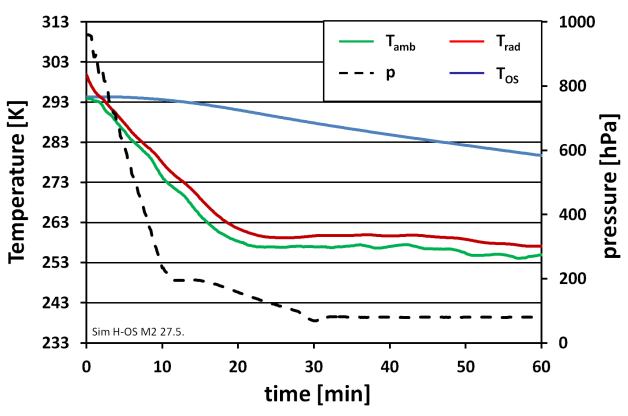

Fig. 11. Simulated thermal behaviour of GBB optical surfaces in two different scenarios. Upper panel: Scenario No. 1 (cold instrument compartment) for (a) GBB-C and (b) for GBB-H. Lower panel: Scenario No. 2 (warm instrument compartment) for (c) GBB-C for (d) GBB-H.

components of a GBB were parameterized as related to their thermal characteristics. The thermal model is a very useful tool to create ideally suited configurations for the in-flight calibration. The thermal behaviour of the optical surface and of the stray light baffle were calculated separately. For selected conditions the calculated values were verified by environmental tests performed in the thermal vacuum test chamber of the Research Centre Juelich. The estimated heat loads for the optical surface (GBB-OS) and for the stray light baffle, respectively, are given in Table 3.

Removing the permanent external heat load on a GBB is not the most difficult task. The internal energy stored in the aluminium mass of one pyramid array $(m=3.8 \mathrm{~kg})$ making up for a temperature difference of $50 \mathrm{~K}$, equals $171 \mathrm{~kJ}$. For the baffle $(m=1.8 \mathrm{~kg})$ it equals $81 \mathrm{~kJ}$, respectively. In order to cool the optical surface of one GBB from $+20^{\circ} \mathrm{C}$ to $-30^{\circ} \mathrm{C}$ an average cooling power of about $50 \mathrm{~W}$ is needed to reach the desired temperature in less than one hour.

\subsection{Cooling rates and power consumption}

The most critical part in the thermal management is the heat dissipation on the hot side of the TECs. The performance and thus the achievable minimum temperature are highly dependent on the ability to transfer the produced heat to the ambient air. Natural convection as well as forced convection are unfortunately reduced due to the low pressure at flight level $(p<200 \mathrm{hPa})$. Table 4 gives temperatures and cooling rates for the GBB optical surface at several points in time
Table 3. Estimated heat loads for the GBB.

\begin{tabular}{|c|c|c|c|c|c|c|}
\hline \multicolumn{6}{|c|}{ (a) Heat load portions } & \multirow[b]{2}{*}{$\begin{array}{c}\text { Convection @ } \\
p=200(80) \mathrm{hPa} \\
{\left[\mathrm{mW} \mathrm{K}^{-1}\right]}\end{array}$} \\
\hline \multicolumn{2}{|c|}{ Element } & \multicolumn{2}{|c|}{$\begin{array}{l}\text { Thermal } \\
\text { conduction } \\
{\left[\mathrm{mW} \mathrm{K}^{-1}\right]}\end{array}$} & \multicolumn{2}{|c|}{$\begin{array}{l}\text { Radiation } \\
{\left[\mathrm{mW} \mathrm{K}^{-4}\right]}\end{array}$} & \\
\hline \multirow{2}{*}{\multicolumn{2}{|c|}{$\begin{array}{l}\text { GBB-OS } \\
\text { GBB-Baffle }\end{array}$}} & \multirow{2}{*}{\multicolumn{2}{|c|}{$\begin{array}{l}65 \\
60\end{array}$}} & \multirow{2}{*}{\multicolumn{2}{|c|}{$\begin{array}{c}8 \times 10^{-11} \\
2.5 \times 10^{-10}\end{array}$}} & - \\
\hline & & & & & & 75 \\
\hline \multicolumn{7}{|c|}{ (b) Heat loads for various scenarios (GBB-C) } \\
\hline$T_{\mathrm{amb}}$ & {$\left[{ }^{\circ} \mathrm{C}\right]$} & {$\left[{ }^{\circ} \mathrm{C}\right]$} & {$[\mathrm{hPa}]$} & $\begin{array}{l}\text { GBB-OS } \\
\text { heat load } \\
{[\mathrm{W}]}\end{array}$ & $\begin{array}{c}\text { GBB-Baffle } \\
\text { heat load } \\
{[\mathrm{W}]}\end{array}$ & $\begin{array}{c}\text { Total } \\
\text { heat load } \\
{[\mathrm{W}]}\end{array}$ \\
\hline-10 & -10 & -20 & 200 & 0.7 & 1.6 & 2.3 \\
\hline-50 & -50 & -60 & 200 & 0.7 & 1.5 & 2.2 \\
\hline-50 & -50 & -60 & 80 & 0.7 & 1.3 & 2.0 \\
\hline
\end{tabular}

as a function of the electrical current, taking into account changes in ambient temperature and pressure during take-off and flight.

As clearly seen from Table 4, an increase in power from $72 \mathrm{~W}(1.5 \mathrm{~A})$ to $130 \mathrm{~W}(2 \mathrm{~A})$ does not improve the cooling rate. In consequence, the most relevant factor for the cooling rate is the heat capacity of the aluminium structure.

The thermal behaviour of GBB-C was simulated in two different scenarios. Results are shown in Fig. 11a and c. Scenario No. 1 simulates a flight with ambient temperature dropping to $-33^{\circ} \mathrm{C}$ and a final pressure level of $80 \mathrm{hPa}$ representing a flight in a cold Geophysica instrument compartment. In this scenario the TECs of the optical surface are operated 
Table 4. Temperature and cooling rate for the GBB optical surface as a function of the electrical current, taking into account changes in ambient temperature and pressure.

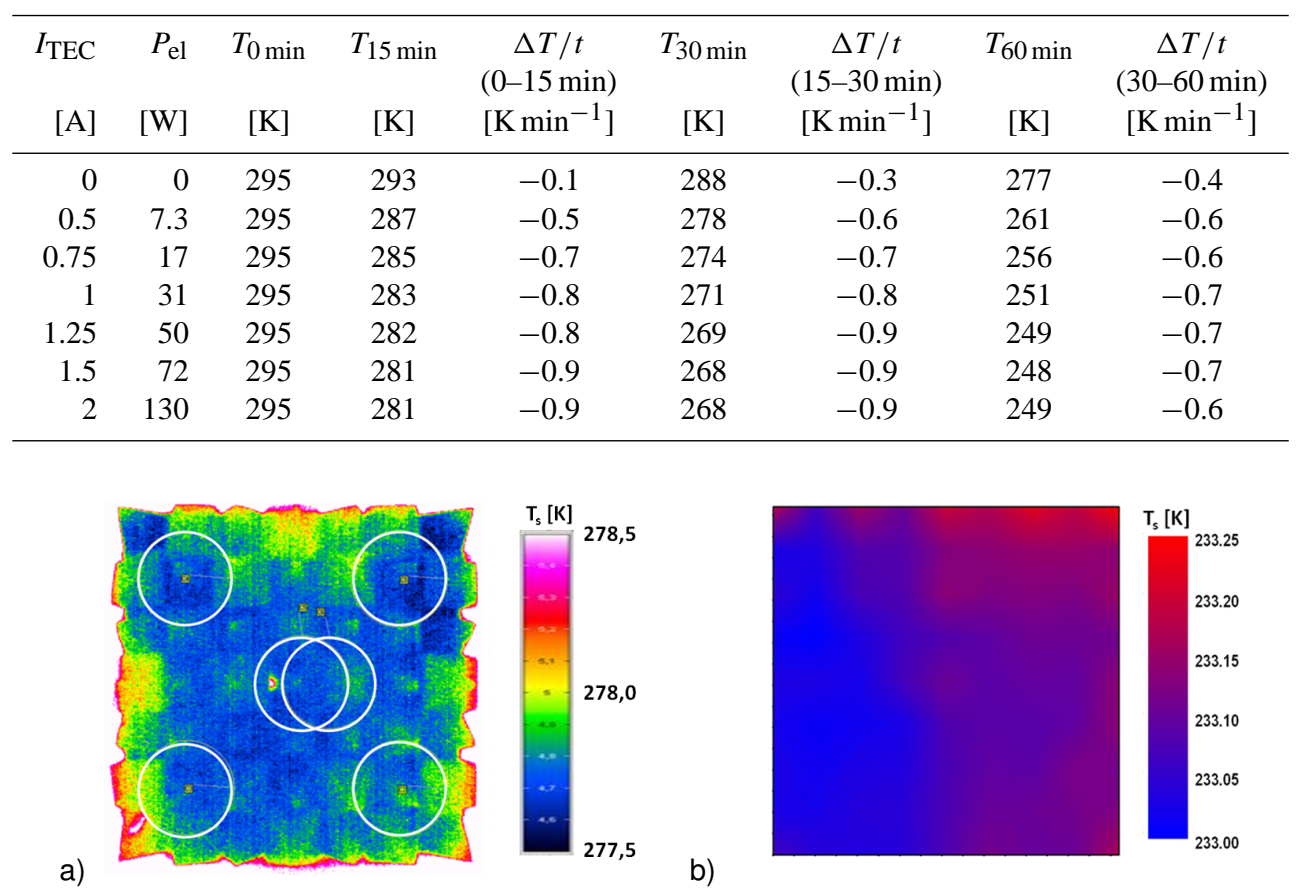

Fig. 12. Radiance temperature distribution of the black optical surface: (a) infrared image of the 2008 prototype taken by a thermographic camera in the lab (ambient $T$ and $p$ ) with the white circles representing the FOV of individual GLORIA detector pixels. (b) GBB-H flight model radiance temperature measured by VIRST at the RBCF of PTB $\left(T_{\mathrm{GBB}}=233 \mathrm{~K}\right)$. Depicted is the smoothed distribution of radiance temperature resulting from a measured grid of 11 by 11 points.

with an electrical current of $1.4 \mathrm{~A}$. In scenario No. 2 a flight with ambient temperature dropping to $-18^{\circ} \mathrm{C}$ and a final pressure level of $80 \mathrm{hPa}$ is simulated which corresponds to a flight in a hot Geophysica instrument compartment. In this scenario the TECs of the optical surface are operated with an electrical current of $2 \mathrm{~A}$, which is equal to $130 \mathrm{~W}$ of electrical power. The thermal behaviour of GBB-H was also simulated for the same scenarios. Results are shown in Fig. 11b and d. Scenario No. 1 compares to scenario No. 1 of the GBB-C simulation. In this scenario the TECs of the optical surface are operated with an electrical current of $0.9 \mathrm{~A}$. In scenario No. 2 which compares to scenario No. 2 of GBB-C, all TECs are switched off and cooling occurs passively only.

\subsection{Spatial homogeneity of optical surface radiance temperature}

As required for optimal performance, the temperature gradient on the black optical surface as seen by the individual detector pixels should be less than $150 \mathrm{mK}$. From the infrared image of the 2008 prototype optical surface at a mean temperature of about $278 \mathrm{~K}$ taken by a thermographic camera in the lab at ambient pressure (Fig. 12a), a maximum temperature gradient of $80 \mathrm{mK}$ between different FOVs of individual detector pixels could be derived. As the convection process inside the blackbody is not reduced in the lab environment and the absolute temperature is higher than under flight conditions, these findings only give an indication for the expected spatial inhomogeneity in radiance temperature during in-flight calibration at flight level.

In Fig. $12 b$ the GBB-H radiance temperature measured by the Vacuum InfraRed Standard radiation Thermometer (VIRST) at the Reduced Background Calibration Facility (RBCF) of PTB is shown with the pyramid array at $233 \mathrm{~K}$, while the pressure inside of the RBCF was set to $100 \mathrm{hPa}$. Depicted is the smoothed distribution of radiance temperature resulting from a measured grid of 11 by 11 points. Compared to the prototype, spatial temperature homogeneity could be improved, although there is still a residual temperature gradient due to the fact that the individual temperature control of the four sectors did not work perfectly.

During the first radiance temperature measurements with VIRST at the RBCF for the characterisation of the GBBs, the homogeneity in radiance temperature across the black optical surface of GBB-C and GBB-H was checked at designated positions. The small red circles in Fig. 6 indicate those measurement positions, where the VIRST measurement field of $10 \mathrm{~mm}$ in diameter with its spectral range extending from 8 to $14 \mu \mathrm{m}$ was centred around. Results for two selected operating 
Table 5. Radiance temperature measurements of the GBB optical surface at $-30^{\circ} \mathrm{C}$ for GBB-C and at $0{ }^{\circ} \mathrm{C}$ for $\mathrm{GBB}-\mathrm{H}$, respectively. Measurement positions are given in Fig. 6.

\begin{tabular}{lllr}
\hline GBB-C & at $-30{ }^{\circ} \mathrm{C}$ & GBB-H & at $0{ }^{\circ} \mathrm{C}$ \\
\hline S110 (centre, apex) & -29.630 & S210 (centre, apex) & 0.001 \\
S120 (centre, base) & -29.603 & S220 (centre, base) & 0.001 \\
\hline S111 (top right, apex) & -29.440 & S211 (top right, apex) & 0.031 \\
S121 (top right, base) & -29.470 & S221 (top right, base) & 0.030 \\
\hline S112 (bottom right, apex) & -29.630 & S212 (bottom right, apex) & -0.008 \\
S122 (bottom right, base) & -29.600 & S222 (bottom right, base) & -0.010 \\
\hline S113 (bottom left, apex) & -29.800 & S213 (bottom left, apex) & -0.004 \\
S123 (bottom left, base) & -29.760 & S223 (bottom left, base) & -0.005 \\
\hline S114 (top left, apex) & -29.322 & S214 (top left, apex) & 0.058 \\
S124 (top left, base) & -29.360 & S224 (top left, base) & 0.076 \\
\hline
\end{tabular}

temperatures of the GBBs are listed in Table 5. The temperature gradient between the pyramid apex and its base is less than $40 \mathrm{mK}$ for GBB-C at $-40^{\circ} \mathrm{C}$ and less than $20 \mathrm{mK}$ for $\mathrm{GBB}-\mathrm{H}$ at $0^{\circ} \mathrm{C}$ indicating the good homogeneity within one pyramid. Also the overall spatial homogeneity in radiance temperature at $0^{\circ} \mathrm{C}$ was already better than the desired $150 \mathrm{mK}$, whereas at $-30^{\circ} \mathrm{C}$ deviations of about $400 \mathrm{mK}$ are visible. This deviation should be easily accounted for by regulating the various TECs with respect to the PRTs, what had not been done for these specific measurements. In this case only a single temperature setting was provided for the thermal control plate of the optical surface. Improvements are expected when (a) the TEC control electronics is optimised and (b) the temperature setting can be higher resolved.

\subsection{Thermal vacuum test chamber results}

To assure optimal performance of the GLORIA in-flight blackbody calibration system on board an aircraft, it is important to know the specific thermal properties in order to get the most direct control over its behaviour during the mission. In order to simulate realistic flight conditions, environmental tests were performed in the thermal vacuum test chamber of Research Centre Juelich. One goal was to minimise time for cool-down, so operational readiness is accomplished as soon as possible. Unfortunately cool-down cannot begin before aircraft take-off due to the risk of water vapour contamination or even ice formation.

The thermal characteristics of the GBBs during the various phases of a flight were investigated in order to ensure all components will withstand the environmental conditions at flight level, to validate the thermal model, and to acquire a solid data base for the development of an in-flight operational concept.

In order to measure the influence of convection, the GBBs were operated with open and closed apertures. No significant differences were detected either in the cooling rates or the required power in the calibration mode. Figure 13a shows the thermal behaviour of the GBB-C optical surface during a simulated ascent assuming that the final ambient temperature in the aircraft bay will be $-33^{\circ} \mathrm{C}$. The TECs of the optical surface were operated with $1.3 \mathrm{~A}$ which corresponds to an electrical power of less than $50 \mathrm{~W}$. After one hour the optical surface of GBB-C reached a temperature of $-20^{\circ} \mathrm{C}$ while the stray light baffle cooled down to $-40^{\circ} \mathrm{C}$ manifesting that due to the lower mass the cooling of the baffle is not a time-critical procedure.

Although GBB-H was operated with lower power $(<25 \mathrm{~W})$, GBB-H optical surface reached a temperature of $-16^{\circ} \mathrm{C}$ after $60 \mathrm{~min}$ which is just $4 \mathrm{~K}$ above the GBB-C temperature. As shown in Fig. 13b, the temperature of the radiator $\left(T_{\mathrm{rad}}\right)$ is significantly lower due to the lower dissipating excess heat. Comparing the test results with the thermal model (see Fig. 11) excellent agreement is found.

Tests under various extreme conditions were also performed. In one of the tests the two GBBs were operated in very different modes: GBB-C was powered with the maximal possible power of up to $120 \mathrm{~W}$ whereas GBB-H was just cooled passively. Results are shown in Fig. 13c and d. After one hour the optical surface of GBB-C reached a temperature of $-18.5^{\circ} \mathrm{C}$ while the stray light baffle cooled down to $-33^{\circ} \mathrm{C}$. $T_{\text {rad }}$ is significantly higher $\left(+17^{\circ} \mathrm{C}\right)$ compared to the test shown in Fig. 13a, and b due to the higher dissipating excess heat. A massive influence of the ambient pressure is also clearly seen in Fig. 13c. When the ambient pressure drops from 200 to $80 \mathrm{hPa}, T_{\text {rad }}$ increases from 9 to $20^{\circ} \mathrm{C}$. The passive cooling of GBB-H results in a temperature of $-4{ }^{\circ} \mathrm{C}$ after $60 \mathrm{~min}$. Again, comparing the results for the tested extreme conditions with the thermal model (see Fig. 11c and d) excellent agreement is reached.

With respect to optimising the performance for future flights on board an aircraft, the cooling of the optical surfaces requires particular attention. Comparing the cooling rates for the GBB-C optical surface during ascent (the first 

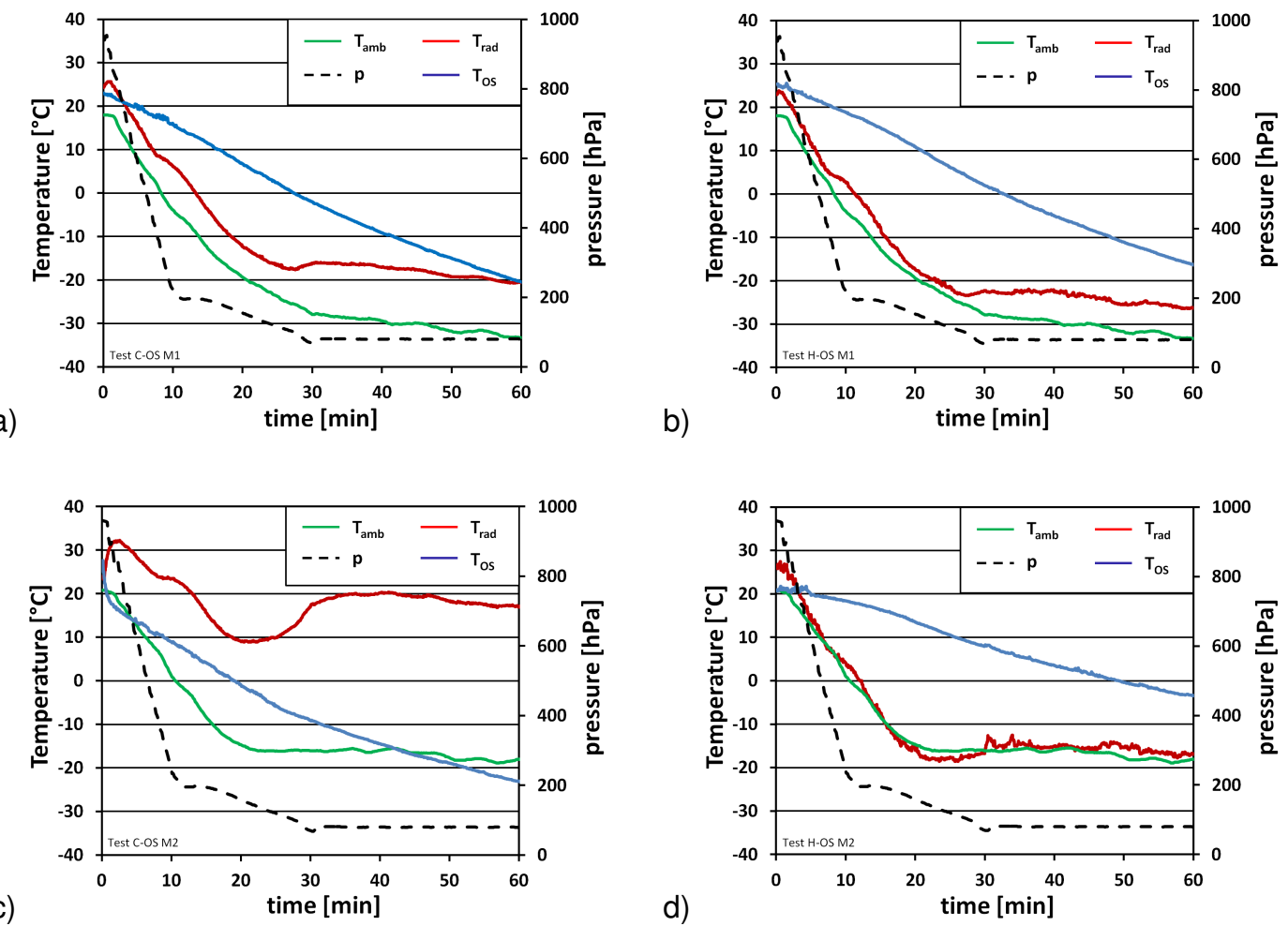

Fig. 13. Thermal behaviour during ascent simulation test. Upper panel: Scenario No. 1 (cold instrument compartment, final $\left.T_{\mathrm{amb}}=-33^{\circ} \mathrm{C}\right)$ of (a) GBB-C optical surface with TEC power $<50 \mathrm{~W}$ and (b) GBB-H optical surface with TEC power $<25 \mathrm{~W}$. Lower panel: Scenario No. 2 (warm instrument compartment, final $T_{\mathrm{amb}}=-18^{\circ} \mathrm{C}$ ) of (c) GBB-C optical surface with TEC power $<120 \mathrm{~W}$ and (d) GBB-H optical surface with TEC power $=0 \mathrm{~W}$.

$25 \mathrm{~min}$ of the flight) in various scenarios, values from 0.7 to $1.1 \mathrm{~K} \mathrm{~min}^{-1}$ were measured, whereas for the stray light baffle an almost constant linear gradient of about $1.8 \mathrm{~K} \mathrm{~min}^{-1}$ is found. Operating the TECs of GBB-C without the cooling fans will not lead to a stable temperature of the optical surface within the calibration temperature range.

After having reached the desired temperature level, temperature stabilisation is required. Since less power is needed to keep the temperature constant, $T_{\text {rad }}$ drops, leading to a smaller temperature difference between $T_{\mathrm{h}}$ and $T_{\mathrm{c}}$ of the TECs and thus even less power over time is required until equilibrium is reached. Table 6 gives the electrical power necessary to keep a constant and homogeneous temperature field for calibration.

Figure 14 shows the results for the first part of a simulated HALO flight. An ascent to $10 \mathrm{~km}$ in $10 \mathrm{~min}$ and a further rise to a final pressure level of $150 \mathrm{hPa}$ was simulated, while the temperature inside the instrument compartment dropped to $223 \mathrm{~K}$. After about $45 \mathrm{~min}$ GBB-H reached its target temperature of $255 \mathrm{~K}$ and was stabilised. It took about two hours for GBB-C to reach $218 \mathrm{~K}$, which was $5 \mathrm{~K}$ below ambient temperature. The minimum temperature was reached after about three hours when the GBB electronics stabilises GBB-C as well. Details are given in Fig. 14b. Again, the temperature in sector No. 4 could not be controlled perfectly.

\section{ITS-90 traceability}

To achieve the required low uncertainty of less than $100 \mathrm{mK}$ in the optical surface radiance temperature of the GBBs, a calibration of the used contact thermometers and performing corrections for non-ideal emissivity, possible thermal gradients and temperature inhomogeneities is not sufficient. In fact, only a direct comparison of the surface radiance temperature and the spectral radiance of the GBBs with the blackbody radiation coming from high-quality cavity radiators linked to the primary national standards of radiance temperature yields sufficiently small uncertainties and strict traceability to the International Temperature Scale (ITS-90). Furthermore, the systematic long-term investigation of the radiometric performance of the GLORIA in-flight blackbody calibration system at the highest possible metrological standard will enable further development and improvement of the blackbody calibration sources, also for future applications on board of balloons and satellites.

Following this line of thought, the GLORIA in-flight blackbody calibration system has been investigated and 
Table 6. Power required for GBB optical surface temperature stabilisation.

\begin{tabular}{ccccccc}
\hline $\begin{array}{c}\text { Ambient } \\
\text { temperature } \\
{\left[{ }^{\circ} \mathrm{C}\right]}\end{array}$ & $\begin{array}{c}\text { Ambient } \\
\text { pressure } \\
{[\mathrm{hPa}]}\end{array}$ & $\begin{array}{c}\text { Optical surface } \\
\text { temperature } \\
{\left[{ }^{\circ} \mathrm{C}\right]}\end{array}$ & $\Delta T$ & $\begin{array}{c}\text { Electrical } \\
\text { current } \\
{[\mathrm{K}]}\end{array}$ & $\begin{array}{c}\text { Total power } \\
\text { for cooling } \\
{[\mathrm{W}]}\end{array}$ & $\begin{array}{c}\text { Total power } \\
\text { for GBB-C } \\
{[\mathrm{W}]}\end{array}$ \\
\hline \multicolumn{7}{c}{ (a) GBB-C } \\
\hline-45 & 80 & -54 & 9 & 0.25 & 8.5 & 26.5 \\
-46 & 80 & -59 & 13 & 0.45 & 12 & 30 \\
-46 & 80 & -64 & 18 & 0.60 & 16 & 34 \\
\hline-25 & 80 & 0 & 25 & 0.7 & 11 & 18 \\
\hline-48 & 230 & 0 & 48 & 0.9 & 27 & 34 \\
\hline-48 & 230 & -21 & 27 & 0.8 & 14 & 21 \\
\hline
\end{tabular}
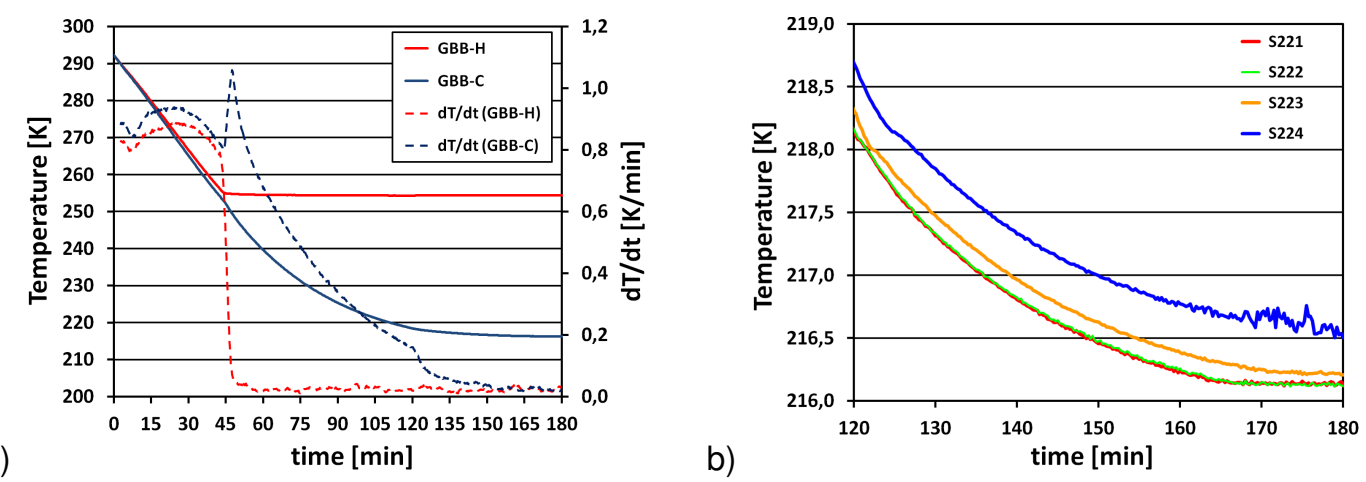

Fig. 14. GBB-HALO flight simulation test: (a) GBB-C temperature (T-sensor S110) and GBB-H temperature (T-sensor S210) during the first three hours of the flight, (b) thermal behaviour of GBB-C optical surface after two flight hours.

calibrated in the Reduced Background Calibration Facility (RBCF) of PTB (Monte et al., 2009a, b). The RBCF allows the calibration of spectral radiance and radiance temperature under environmental conditions similar to those during flight operation. The calibration is performed by direct comparison of the blackbody calibration sources with reference cavity blackbody radiators (emissivity $>0.9997$ ) of known radiance temperature. The radiance temperatures of the GBB optical surfaces were determined in the range from -50 to $0^{\circ} \mathrm{C}$ with an uncertainty of less than $100 \mathrm{mK}$ (two sigma).

For the measurement of spectral radiance this comparison is performed via a Fourier Transform Spectrometer, for the radiance temperature via the broadband radiance thermometer VIRST ( 8 to $14 \mu \mathrm{m}$ ) as transfer instruments (Gutschwager et al., 2008). With a transfer radiation thermometer the radiance temperature of the reference cavity blackbody radiators of the RBCF is directly linked to the heat-pipe blackbodies of PTB (?)hollandt03, the primary national SI standards of radiance temperature in Germany. The radiance temperature of the heat-pipe blackbodies has been compared to the radiance temperature scale of other national metrology institute in international comparisons to assure their worldwide consistency at the highest metrological standard (Gutschwager et al., 2013).

\section{Summary and conclusions}

The GLORIA instrument is an airborne infrared limb imager for investigating the UTLS. In order to retrieve trace species with a sufficient degree of accuracy for atmospheric process studies, the target requirement for the GLORIA calibration is an uncertainty in absolute spectral radiances of $1 \%$ (threshold $=3 \%$ ). On this basis the following requirements are inferred for the GLORIA in-flight calibration system: For the intended two-point calibration, two identical weightoptimised high-precision blackbody radiation sources (GBB$\mathrm{C}$ and GBB-H) shall be used, which are independently controlled at two different temperatures and emit radiation in the range of the atmospheric infrared radiance emissions. Each blackbody shall supply a large-area black optical surface $(126 \mathrm{~mm} \times 126 \mathrm{~mm})$ with an emissivity greater than 0.997 for calibrating GLORIA's two-dimensional detector array at well-defined radiance temperatures with an uncertainty of less than $100 \mathrm{mK}$, stabilised to better than $25 \mathrm{mK} \mathrm{min}^{-1}$. The temperature of the cold blackbody (GBB-C) shall be at least 
$10 \mathrm{~K}$ below ambient temperature and the temperature difference between the two calibration sources shall be at least $40 \mathrm{~K}$.

The Atmospheric Physics group at the University of Wuppertal designed and built the GLORIA in-flight blackbody calibration system for its deployment on board different research aircraft. In order to meet the specification of the required emissivity, the optical surface of a GBB consists of an array with 49 individual pyramids of three different shapes. The chosen geometry ensures multiple reflection of all incoming radiation for the whole surface except the pyramid tips. The NEXTEL-Velvet Coating used as surface finish for the pyramids as well as for the inner walls of the casing has a nearly Lambertian radiation characteristic and a measured emissivity of greater than 0.967 . The aluminium casing which surrounds the optical surface is partly thermally decoupled, while the front part serves as a stray light baffle. The stray light baffle is operated at a slightly lower temperature in order to act as a water vapour trap to inhibit condensation on the black optical surface. The calculated effective emissivity of the black pyramid array in a medium-size box is 0.9996, which is well above the requirement.

For temperature control of the black optical surface, Thermo-Electric Coolers (TECs) are used offering the advantage of avoiding cryogens and mechanical coolers. An additional benefit of TECs is the dual utilisation for cooling and heating by just switching the direction of the electrical current. The selected TECs are precisely tailored to the limited available electrical power and are capable of providing the required temperatures. An assembly of four two-stage Peltron 128A0020 is used to generate a stable and homogeneous radiance temperature field across the black optical surface of each GBB. For the temperature control of the stray light baffle two single-stage TEC type Peltron 128A2427 are applied. The temperature is measured by PT100 resistance thermometers which are directly calibrated to the radiance temperature emitted from the optical surface versus the national radiance calibration standard. Strict traceability to the International Temperature Scale (ITS-90) has been attained by various measurements at PTB, the German national metrology institute. The achieved spatial temperature homogeneity of $\pm 0.075 \mathrm{~K}$, which fully complies with the requirements, can further be improved by modifying the software of the GBB electronics, which has been developed and implemented at IPE of KIT. The temperature measurements yield a noise of $\pm 0.025 \mathrm{~K}$ while the temperature drift was found to be less than $25 \mathrm{mK}$ in $30 \mathrm{~min}$. The overall performance of the GLORIA blackbody calibration sources is far beyond the required uncertainty of less than $100 \mathrm{mK}$.

The GLORIA in-flight calibration system was extensively tested in numerous thermal vacuum tests proving that it can be operated very well in the hostile environment of the UTLS region with mutable low temperature and pressure. The comprehensive thermal model is a useful tool to further increase the efficiency of the thermal control system. It has been demonstrated that the GLORIA in-flight blackbody calibration system is eminently suitable for the in-flight calibration of the GLORIA instrument at the highest metrological standard. It meets or even exceeds the stringent requirements for a successful deployment on board various aircraft such as the German HALO or the Russian M55 Geophysica. Modified software for temperature control of the four sectors of the pyramid array may further improve the homogeneity of the radiance temperature field across the black optical surface. In order to reduce the time before the GLORIA in-flight blackbody calibration system is operational at flight level, either more electrical power must be made available or, in a new approach, the design of the optical surface is to be changed for weight optimisation, so that thermal mass is further reduced. Recurring measurements at PTB, the German national metrology institute, will ensure a continuous quality and complete traceability to the International Temperature Scale (ITS-90).

Acknowledgement. Part of this work has been supported by the European Metrology Research Programme (EMRP) within the joint research project Metrology for Earth Observation and Climate (MetEOC). The EMRP is jointly funded by the EMRP participating countries within EURAMET and the EU.

Edited by: C. von Savigny

\section{References}

ESA: Candidate Earth Explorer Core Missions - Report for Assessment: PREMIER - PRocess Exploitation through Measurements of Infrared and millimetre-wave Emitted Radiation, vol. SP1313/5, ESA Publications Division, ESTEC, Noordwijk, the Netherlands, 2008.

ESA: Report for mission selection: PREMIER, vol. SP-1324/3, ESA Publications Division, ESTEC, Noordwijk, the Netherlands, 2012.

Friedl-Vallon, F., Riese, M., Maucher, G., Lengel, A., Hase, F., Preusse, P., and Spang, R.: Instrument concept and preliminary performance analysis of GLORIA, Adv. Space Res., 37, 22872291, doi:10.1016/j.asr.2005.07.075, 2006.

Friedl-Vallon, F., Gulde, T., Hase, F., Kleinert, A., Kulessa, T., Maucher, G., Neubert, T., Olschewski, F., Piesch, C., Preusse, P., Rongen, H., Sartorius, C., Schneider, H., Schönfeld, A., Tan, V., Bayer, N., Blank, J., Dapp, R., Ebersoldt, A., Fischer, H., Guggenmoser, T., Höpfner, M., Kaufmann, M., Kretschmer E., Nordmeyer, H., Oelhaf, H., Orphal, J., Riese, M., Schardt, G., Schillings, J., Sha, M. K., Suminska-Ebersoldt, O., and Ungermann, J.: Instrument concept of the imaging Fourier transform spectrometer GLORIA, Atmos. Meas. Tech., in preparation, 2014.

Gettelman, A., Hoor, P., Pan, L. L., Randell, W. J., Hegglin, M. I., and Birner, T.: The extra tropical upper troposphere and lower stratosphere, Rev. Geophys., 49, RG3003, doi:10.1029/2011RG000355, 2011. 
Gutschwager, B., Hollandt, J., Jankowski, T., and Gaertner, R.: A vacuum infrared standard radiation thermometer at the PTB, Int. J. Thermophys., 29, 330-340, doi:10.1007/s10765-0070349-x, 2008.

Gutschwager, B., Theocharous, E., Monte, C., Adibekyan, A., Reiniger, M., Fox, N. P., and Hollandt, J.: Comparison of the radiation temperature scales of the PTB and the NPL in the temperature range from $-57^{\circ} \mathrm{C}$ to $50^{\circ} \mathrm{C}$, Meas. Sci. Technol., 24, 065002, doi:10.1088/0957-0233/24/6/065002, 2013.

Hollandt, J., Friedrich, R., Gutschwager, B., Taubert, D., and Hartmann, J.: High-accuracy radiation thermometry at the National Metrology Institute of Germany - the PTB, High Temp.-High Press., 35/36, 379-415, 2003/2004.

Howell, J. R.: A catalog of radiation heat transfer configuration factors, available at: http://www.engr.uky.edu/rtl/Catalog/(last access: 20 March 2013), 2010.

ISO/IEC: Guide 98-3:2008 Uncertainty of measurement - Part 3: Guide to the expression of uncertainty in measurement, JCGM Joint Committee for Guides in Metrology, Genf, 2008.

Lohrengel, J. and Todtenhaupt, R.: Waermeleitfaehigkeit, Gesamtemissionsgrade und spektrale Emissionsgrade der Beschichtung Nextel-Velvet-Coating 811-21 (RAL90015 tiefschwarz matt), PTB-Mitt., 106, 259-265, 1996.

Monte, C., Gutschwager, B., and Hollandt, J.: The reduced background calibration facility for detectors and radiators at the Physikalisch-Technische Bundesanstalt, in: Proc. of SPIE, Vol. 7474, Sensors, Systems, and Next-Generation Satellites XIII, 747414, edited by: Meynart, R., Neeck, S. P., and Shimoda, H., Berlin, Germany, doi:10.1117/12.830454, 2009a.

Monte, C., Gutschwager, B., Morozova, S., and Hollandt, J.: Radiation thermometry and emissivity measurements under vacuum at the PTB, Int. J. Thermophys., 30, 203-219, doi:10.1007/s10765008-0442-9, 2009b.

Olschewski, F., Rolf, C., Steffens, P., Kleinert, A., Piesch, C., Ebersoldt, A., Monte, C., Gutschwager, B., Hollandt, J., Preusse, P., Friedl-Vallon, F., and Koppmann, R.: In-flight blackbody calibration sources for the GLORIA interferometer, in: Proc. SPIE 8511, Infrared Remote Sensing and Instrumentation XX, Marija Strojnik; Gonzalo Paez, San Diego, California, USA, 85110I, doi:10.1117/12.928194, 2012.

Ploeger, F., Fueglistaler, S., Grooß, J.-U., Günther, G., Konopka, P., Liu, Y. S., Müller, R., Ravegnani, F., Schiller, C., Ulanovski, A., and Riese, M.: Insight from ozone and water vapour on transport in the tropical tropopause layer (TTL), Atmos. Chem. Phys., 11, 407-419, doi:10.5194/acp-11-407-2011, 2011.

Preusse, P., Schroeder, S., Hoffmann, L., Ern, M., Friedl-Vallon, F., Ungermann, J., Oelhaf, H., Fischer, H., and Riese, M.: New perspectives on gravity wave remote sensing by spaceborne infrared limb imaging, Atmos. Meas. Tech., 2, 299-311, doi:10.5194/amt-2-299-2009, 2009.
Riese, M., Friedl-Vallon, F., Spang, R., Preusse, P., Schiller, C., Hoffmann, L., Konopka, P., Oelhaf, H., von Clarmann, T., and Höpfner, M.: GLObal limb Radiance Imager for the Atmosphere (GLORIA): scientific objectives, Adv. Space Res., 36, 989-995, doi:10.1016/j.asr.2005.04.115, 2005.

Riese, M., Ploeger, F., Rap, A., Vogel, B., Konopka, P., Dameris, M., and Forster, P.: Impact of uncertainties in atmospheric mixing on simulated UTLS composition and related radiative effects, J. Geophys. Res., 117, D16305, doi:10.1029/2012JD017751, 2012.

Riese, M., Preusse, P., Oelhaf, H., Friedl-Vallon, F., Hoepfner, M., Hoor, P., Kaufmann, M., Orphal, J., Ploeger, F., Spang, R., Ungermann, J., Vogel, B., and Woiwode, W.: The Gimballed Limb Observer for Radiance Imaging of the Atmosphere (GLORIA): Scientific Objectives, Atmos. Meas. Tech., in preparation, 2014.

Solomon, S., Qin, D., Manning, M., Chen, Z., Marquis, M., Averyt, K. B., Tignor, M., and Miller, H. L. (Eds.): Technical Summary in Climate Change 2007: the Physical Science Basis, Contributions of Working Group I to the Fourth Assessment Report of the Intergovernmental Panel on Climate Change, Cambridge University Press, Cambridge, UK and New York, NY, USA, 2007.

Solomon, S., Rosenlof, K. H., Portmann, R. W., Daniel, J. S., Davis, S. M., Sanford, T. J., and Plattner, G.-K.: Contributions of stratospheric water vapor to decadal changes in the rate of global warming, Science, 327, 1219-1223, doi:10.1126/science.1182488, 2010.

Stevenson, D. S., Dentener, F. J., Schultz, M. G., Ellingsen, K., van Noije, T. P. C., Wild, O., Zeng, G., Amann, M., Atherton, C. S., Bell, N., Bergmann, D. J., Bey, I., Butler, T., Cofala, J., Collins, W. J., Derwent, R. G., Doherty, R. M., Drevet, J., Eskes, H. J., Fiore, A. M., Gauss, M., Hauglustaine, D. A., Horowitz, L. W., Isaksen, I. S. A., Krol, M. C., Lamarque, J.F., Lawrence, M. G., Montanaro, V., Pitari, G., Prather, M. J., Pyle, J. A., Rast, S., Rodriguez, J. M., Sanderson, M. G., Savage, N. H., Shindell, D. T., Strahan, S. E., Sudo, K., and Szopa, S.: Multimodel ensemble simulations of present-day and near-future tropospheric ozone, J. Geophys. Res., 111, 148-227, doi:10.1029/2005JD006338, 2006.

Ungermann, J., Blank, J., Lotz, J., Leppkes, K., Hoffmann, L., Guggenmoser, T., Kaufmann, M., Preusse, P., Naumann, U., and Riese, M.: A 3-D tomographic retrieval approach with advection compensation for the air-borne limb-imager GLORIA, Atmos. Meas. Tech., 4, 2509-2529, doi:10.5194/amt-4-2509-2011, 2011. 